This study examined the expression of inducible nitric oxide synthase (iNOS) and transforming growth factor-beta (TGF- $\beta$ ) in macrophage infiltrates within crush-injured digital flexor tendon and synovium of control rats and rats treated with $N(G)$-nitrol-arginine methyl ester (L-NAME) $(5 \mathrm{mg} / \mathrm{kg})$. Release of TGF- $\beta$ from organ cultures of tendon, muscle, and synovium, and the effects of L-NAME treatment (in vitro and in vivo), on adhesion of peritoneal macrophages to epitenon monolayers were also investigated. The results showed that during normal tendon healing the levels of TGF- $\beta$ are high at first and gradually decrease after 3 weeks of injury to slightly above control uninjured levels. However, when L-NAME was administered at the time of injury, the macrophage infiltrates were expressing high levels of TGF- $\beta$ even at 5 weeks after the injury, with no evidence of reduction. In the standard injury, iNOS activity was greatest at the acute phase of the inflammatory response and then gradually returned to normal. Treatment with L-NAME, however, resulted in inhibition of iNOS activity at 3 days and a reduction in the activity at the later time points examined after injury. We also found greatly increased levels of adhesion of peritoneal macrophages from L-NAME-treated rats to epitenon monolayers in vitro, which reflect a chronic imbalance in expression of TGF- $\beta$, which is overexpressed, and nitric oxide, which is underexpressed. The results of the current study show that formation of nitric oxide is an important event in the course of tendon healing since its inhibition results in chronic inflammation and fibrosis due to an imbalance in TGF- $\beta$ expression in vivo.

Key words: Tendon, Transforming growth factor-beta, Inducible nitric oxide synthase, Crush injury, Adhesion, Fibrosis

\section{Expression of nitric oxide synthase and transforming growth factor-beta in crush- injured tendon and synovium}

\author{
Homa Darmani ${ }^{1, C A}$, James Crossan², \\ Sarah D. McLellan², Dominic Meek ${ }^{2}$ and \\ Adam Curtis ${ }^{3}$
}

1Department of Applied Biology, Faculty of Science, Jordan University of Science and Technology, P.O. Box 3030, Irbid 22110, Jordan; ${ }^{2}$ Department of Orthopaedic Surgery, Western Infirmary, Glasgow, UK; ${ }^{3}$ Centre for Cell Engineering, Department of Infection and Immunity, Glasgow University, Glasgow, UK

\author{
${ }^{\mathrm{CA}}$ Corresponding Author \\ Tel: +962795978834 \\ Fax: +962 27278962 \\ E-mail: darmani@just.edu.jo
}

\section{Introduction}

Following tendon injuries, post-trauma fibrous adhesions bind adjacent synovial tissue to injured tendon resulting in subsequent pain, stiffness and disability. It is well established that transforming growth factorbeta (TGF- $\beta$ ) plays an important role in wound healing and fibrosis, ${ }^{1}$ and modulation of TGF- $\beta$ production in tendon healing may provide a mechanism to modulate adhesion formation clinically. ${ }^{2}$ During the early stages of wound healing, downregulation of this effector molecule by administration of antibodies to TGF- $\beta 1$ may reduce adhesion formation between injured tendon and synovium. ${ }^{3}$

TGF- $\beta$ has been reported to induce the inhibition of nitric oxide production by macrophages through decreasing the stability and translation of mRNA for the enzyme nitric oxide synthase and increasing its degradation. ${ }^{4}$ Nitric oxide, a highly reactive free radical produced from the amino acid arginine by the enzyme nitric oxide synthase, ${ }^{5}$ has recently been reported to play a multitude of roles in the regulation of wound healing. ${ }^{6-10}$ Furthermore, inhibition of nitric oxide synthesis has been reported to lead to a decrease in the formation of granulation tissue by wound cells. ${ }^{8}$ Indeed, nitric oxide, known for its pleiotropic effects, has also been reported as a potentially important antifibrotic molecule. ${ }^{11-13}$

We have recently studied the effect of inhibition of nitric oxide production, at the time of injury, on inflammatory cell accumulation and fibrosis around the digital flexor tendon and synovium. ${ }^{14}$ We found that the incidence and severity of fibrocellular adhesions between the tendon and synovium was much more marked in animals treated with $N(\mathrm{G})$-nitro-Larginine methyl ester (L-NAME), which elicited a chronic inflammatory response characterised by a persistent and extraordinarily severe accumulation of large numbers of inflammatory cells in the subcuta- 
neous tissues, in muscle and in tendon. We suggested that these findings could have been indicative of a chronic imbalance in the expression of TGF- $\beta$ (likely to be overexpressed) and nitric oxide (likely to be underexpressed). In this study we examine the expression of inducible nitric oxide synthase (iNOS) and TGF- $\beta$ at different stages of the healing process in standard and L-NAME-treated crush-injured rat digital flexor tendon and synovium. We also measure the release of TGF- $\beta$ from organ cultures of tendon, muscle and synovium and examine the effects of L-NAME treatment (in vitro and in vivo) on adhesion of peritoneal macrophages to epitenon monolayers.

\section{Materials and methods}

\section{Reagents}

Tissue culture reagents were purchased from Gibco BRL (Life Technologies, Paisley, UK). All other reagents were purchased from Sigma Chemical Co. (Poole, UK), unless otherwise stated.

\section{Animal model}

Female Wistar rats weighing in the range of 250-300 $\mathrm{g}$ were anaesthetised using Halothane, and under tourniquet control a longitudinal incision was made in the plantar surface of the hindpaw and extended along the line of the middle digit to expose the synovial canal. A standard crush injury was then applied with Adson's forceps along the length of the flexor tendons of the middle digit of the hindpaw and the overlying muscle and synovium. The wound was sutured using a continuous nylon suture and the animals were allowed to mobilise without restriction following the procedure. The animals were then sacrificed by $\mathrm{CO}_{2}$ asphyxiation followed by cervical dislocation at various time points following injury.

\section{Control uninjured group}

Five animals were sacrificed for histology and five animals for TGF- $\beta$ determinations by enzyme-linked immunosorbent assay (ELISA).

\section{Crush injury group}

Twenty animals received an intraperitoneal injection of isotonic saline immediately following crush injury. Five animals were then sacrificed after 3 days and 2 and 5 weeks, and the paws were then processed for histology. Peritoneal macrophages were isolated from these animals for the adhesion assay. The remaining five animals were sacrificed after 3 days for TGF- $\beta$ determinations by ELISA.

\section{Crush injury group treated with L-NAME.}

Twenty-five animals received an intraperitoneal injection of L-NAME $(5 \mathrm{mg} / \mathrm{kg})$ immediately following the crush injury. Five animals were then sacrificed after 3 days and 2 and 5 weeks, and the paws were then processed for histology. Peritoneal macrophages from these L-NAME-treated rats were isolated for the adhesion assay. Another group of five animals was sacrificed after 3 days and 5 weeks for determinations of TGF- $\beta$ levels by ELISA.

\section{Preparation of specimens for tissue immunohistochemistry}

Tissue was prepared for histological examination by undertaking a block dissection to include the wounded skin, subcutaneous tissues, tendon, synovium and muscle, all of which were carefully dissected from the underlying bones. The dissected tissues were pinned onto cork to achieve good alignment of the tendons and were then fixed in $10 \%$ neutral buffered formalin and processed for tissue immunohistochemistry.

\section{Tissue immunohistochemistry}

Block dissected specimens, treated as already described, were embedded in OCT medium (Miles Inc., Elkhart, IN, USA) and frozen to $-70^{\circ} \mathrm{C}$. Longitudinal sections, $5 \mu \mathrm{m}$ in thickness, were cut onto slides, allowed to reach room temperature, and then processed for immunohistochemical staining of cells expressing TGF- $\beta$ and iNOS.

\section{Immunohistochemical staining for TGF- $\beta$}

The sections were washed in Tris-buffered saline (TBS), and treated with dilute normal serum for $15 \mathrm{~min}$. The slides were then drained and incubated with anti-TGF- $\beta$ (prepared in TBS and bovine serum albumin) for $1 \mathrm{~h}$ at room temperature. After washing three times in TBS for $5 \mathrm{~min}$, the slides were treated with biotin-conjugated secondary antibody for $45 \mathrm{~min}$ at room temperature. Subsequent to three further 5-min washes in TBS, the sections were incubated with alkaline phosphate-conjugated extravidin (Sigma) at a dilution of 1:1000 for $30 \mathrm{~min}$. The sections were washed three times in TBS and then visualised using fast 5-bromo-4-chloro-3 indolyl phosphate/nitro blue tetrazolium substrate (Sigma). 


\section{Immunohistochemical staining for iNOS}

The sections were washed in TBS, and were treated with dilute normal serum for $15 \mathrm{~min}$. The slides were then drained and incubated with anti-iNOS (prepared in TBS and bovine serum albumin) for $1 \mathrm{~h}$ at room temperature. After washing three times in TBS for $5 \mathrm{~min}$, the slides were processed as already described for TGF- $\beta$.

\section{Preparation of specimens for TGF- $\beta$ determinations}

Dissected tissue (wounded skin, subcutaneous tissues, tendon, synovium and muscle) was carefully separated from the underlying bones. The tissue was minced into small pieces and gently disrupted using a pestle and mortar. Organ cultures were then maintained in serum-free RPMI 1640 supplemented with $100 \mu \mathrm{g} / \mathrm{ml}$ of penicillin, $100 \mathrm{U} / \mathrm{ml}$ of streptomycin, $2.85 \mathrm{mM}$ glutamine and bicarbonate for $24 \mathrm{~h}$ at $37^{\circ} \mathrm{C}$. The accumulation of TGF- $\beta$ was quantitated using ELISA.

\section{Quantification of TGF- $\beta$ by ELISA}

TGF- $\beta$ levels were quantified in tissue culture supernatants using an ELISA kit (Predicta human cytokine ELISAs for TGF- $\beta$; Genzyme, Cambridge, MA, USA). Samples and standards were first diluted and acidified using hydrochloric acid for $1 \mathrm{~h}$ and were then neutralised to $\mathrm{pH} 7.0-7.4$ with sodium hydroxide. Tissue culture fluid and tissue extract were diluted with an equal volume of sample diluent. Then $100 \mu \mathrm{l}$ of activated standards (0, 0.1, 0.64, 1.6, and $4.0 \mathrm{ng} / \mathrm{ml}$ ) and samples were added to a microtitre plate precoated with a mouse monoclonal antibody to TGF- $\beta$, and the plate was sealed and incubated at $37^{\circ} \mathrm{C}$ for $60 \pm 2 \mathrm{~min}$. The samples were then aspirated and the wells washed vigorously with six changes of wash buffer. Excess fluid was then removed by blotting on tissue paper and $100 \mu \mathrm{l}$ of anti-TGF- $\beta$ horseradish peroxidase conjugate was then added and the plate sealed and incubated at $37^{\circ} \mathrm{C}$ for $60 \pm 2 \mathrm{~min}$. The liquid was then aspirated and the wells washed vigorously with six changes of wash buffer. After blotting off excess fluid with tissue, $100 \mu \mathrm{l}$ of substrate reagent (tetramethylbenzidine $(<2 \%)$ in solvent $(<40 \%)$ and $0.03 \%$ hydrogen peroxide in buffered solution) was added to each well and the plate was left at room temperature for $20 \pm 1 \mathrm{~min}$. Next, $100 \mu \mathrm{l}$ of stop solution (acid mixture; $<2 \mathrm{~N}$ ) was added and the absorbance was recorded at $450 \mathrm{~nm}$ using a BioRad multiscan microtitre plate reader (Bio-Rad Laboratories, Richmond, CA, USA). A standard curve was then constructed to quantitate TGF- $\beta$ concentrations in the samples.

\section{Cell culture}

Epitenon cells. Rat epitenon fibroblasts were isolated from the flexor tendons of young adult male Sprague-Dawley rats according to the method of Banes et al., ${ }^{15}$ as described previously. ${ }^{16}$ Cell monolayers were grown to confluence in Glasgow modified Eagle's medium (MEM) supplemented with 10\% calf serum, $100 \mu \mathrm{g} / \mathrm{ml}$ of penicillin, $100 \mathrm{U} / \mathrm{ml}$ of streptomycin, $2.85 \mathrm{mM}$ glutamine and bicarbonate.

Peritoneal macrophage cultures. Control and LNAME-treated rats were sacrificed by $\mathrm{CO}_{2}$ asphyxiation followed by cervical dislocation. Macrophages were obtained from control and L-NAME-treated rats by peritoneal lavage by injection of $20 \mathrm{ml}$ of sterile phosphate-buffered saline (PBS) into the peritoneal cavity. Following a gentle massage of the abdomen, peritoneal macrophages were collected and any contaminating erythrocytes were removed by hypotonic lysis. The cells were then washed twice by centrifugation at 2000 r.p.m. for $2 \mathrm{~min}$ and finally resuspended in serum-free RPMI medium, for adhesion assays. For one part of the study, macrophages were treated with different concentrations of L-NAME $(0-1.85 \mu \mathrm{M})$ for $24 \mathrm{~h}$ at $37^{\circ} \mathrm{C}$ before being used for the adhesion assay.

\section{Adhesion assay}

A suspension of peritoneal macrophages in serumfree RPMI medium was applied onto quiescent, confluent monolayers of rat epitenon cells in 24well plates (total volume, $500 \mu \mathrm{l} /$ well). After incubation for a variable length of time the suspension was aspirated, and the monolayers were rinsed three times with sterile PBS. The total number of adherent monocytes was evaluated by a colourimetric assay ${ }^{17}$ of fixed cells stained with crystal violet. Following coincubations of epitenon monolayers with macrophages for $6 \mathrm{~h}$, the cultures were washed three times in order to remove non-adherent macrophages. They were then fixed with a solution of $1 \%$ glutaraldehyde in PBS for $15 \mathrm{~min}$ at room temperature. The cultures were then air-dried and stained with $0.1 \%(\mathrm{w} / \mathrm{v})$ solution of crystal violet for $30 \mathrm{~min}$ at room temperature. The crystal violet was aspirated and the monolayers were washed in three changes of sterile distilled water. Cells were permeabilised with 1\% Triton X-100 overnight. Aliquots of the resulting solution, containing solubilised nuclear staining crystal violet were transferred to 96-well microtitre plates and subjected to absorbance spectrometry at $595 \mathrm{~nm}$ with a Bio-Rad model 450 microplate reader (Bio-Rad Laboratories, Richmond, CA, USA). Absorbance was found to be proportional to macrophage density after normalisation for the absorbance of parallel, non-coincubated rat epitenon cell monolayers. 


\section{Results}

\section{Expression of iNOS in the healing tendon}

We first looked at iNOS expression in macrophage infiltrates within tissue sections taken from control uninjured rat paws, standard crush-injured rat paws and L-NAME-treated crush-injured rat paws (Table 1). Histological sections of control uninjured paws, immunocytochemically labelled with anti-iNOS antibody, showed basal levels $(+)$ of nitric oxide activity. The iNOS activity in crush injured paws, taken from animals sacrificed 3 days subsequent to injury, at the acute phase of the inflammatory response, was greatly raised $(+++)$ and then gradually returned to normal. When L-NAME had been administered immediately at the time of injury, iNOS activity was abolished (-) in the 3-day crush-injured paws. The iNOS activity in sections taken from 5-week crushinjured paws from animals that had received L-NAME treatment was still weaker $( \pm)$ than that seen in sections of control uninjured paws $(+)$.

\section{Expression of TGF- $\beta$ in the healing tendon}

We next looked at the levels of TGF- $\beta$ expression in macrophage infiltrates within tissue sections taken from control uninjured rat paws, standard crushinjured rat paws and L-NAME-treated crush-injured rat paws (Table 1). In uninjured paws, the synovium and subsynovial tissues did not stain for TGF- $\beta$. Since the tendon matrix normally acts as a repository for this cytokine, there was some evidence of TGF- $\beta$ staining $( \pm)$. Sections of crush-injured paws showed that the majority of the inflammatory cells were expressing TGF- $\beta$, and a strong positive $(+++)$ staining was observed. The expression of TGF- $\beta$ in sections of crush-injured paws taken from animals decreased gradually, and by 5 weeks subsequent to injury the TGF- $\beta$ levels were reduced further but still slightly above that observed in control uninjured paws $(+)$. When L-NAME was administered at the time of injury, a strong expression of TGF- $\beta$ by inflammatory cells was observed at 3 days after injury $(+++)$, and this increase was maintained 5 weeks after injury $(+++)$.

Table 1. Expression of iNOS and TGF- $\beta$ in the healing tendon of standard and L-NAME-treated animals after crush injury of the rat digital flexor tendon and synovium

\begin{tabular}{lcclcc}
\hline Treatment & \multicolumn{2}{c}{ iNOS } & & \multicolumn{2}{c}{ TGF- $\beta$} \\
\cline { 2 - 3 } \cline { 5 - 6 } \cline { 5 - 6 } & Control & L-NAME & & Control & L-NAME \\
\hline Uninjured & \pm & & & + & \\
Crush injury & & & & & - \\
3 days & +++ & +++ & & +++ & - \\
2 weeks & ++ & +++ & & ++ & + \\
5 weeks & + & +++ & & + & \pm \\
\hline
\end{tabular}

\section{Concentration of TGF- $\beta$ in tissue extracts}

We next measured the amounts of TGF- $\beta$ using ELISA from tissue culture supernatants of the tendon, muscle and synovium. Fig. 1 shows the levels of TGF- $\beta$ in control, crush-injured and L-NAME-treated crush-injured paws. TGF- $\beta$ concentrations in crushinjured paws are doubled in comparison with the levels in uninjured paws. Tissue extracts from crushinjured paws showed a $212 \%$ increase in TGF- $\beta$ levels. This is in agreement with the increased staining for TGF- $\beta$ observed in tissue sections of injured paws. When L-NAME was administered immediately at the time of injury, there was a 33\% reduction in the TGF- $\beta$ levels, in comparison with crush-injured paws that had not received L-NAME, at the acute phase of the inflammatory response. The levels of TGF- $\beta$ in tissue extracts from paws taken 5 weeks after injury and L-NAME administration were found to be comparable with those in control uninjured paws.

\section{Effects of in vitro inhibition of iNOS on adhesion of macrophage cells to epitenon monolayers}

Since we had previously found that in vivo treatment with L-NAME resulted in a greater degree of inflammatory cell adhesion to tendon and synovium, ${ }^{14}$ we next looked at the effects of L-NAME treatment of macrophage cells on their subsequent adhesion to epitenon monolayers.

Figure 2 shows the adhesion of peritoneal macrophages to quiescent monolayers of rat epitenon cells. Pre-treatment of macrophages with different concentrations of L-NAME induced statistically significant increases in the adhesion of macrophages to epitenon monolayers, in comparison with control macrophages that had not been pre-treated with L-NAME.

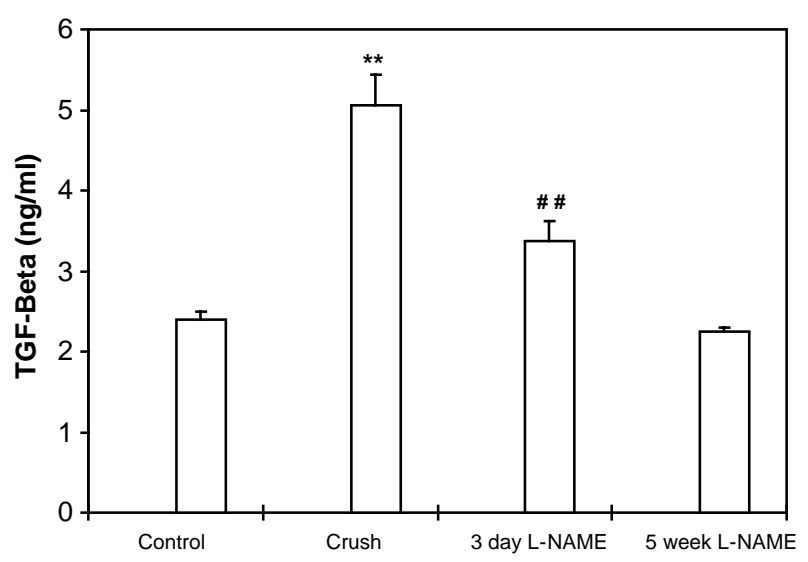

FIG. 1. TGF- $\beta$ concentrations in tendon organ cultures from control uninjured rat paws, crush-injured rat paws ( 3 days after injury) and crush-injured rat paws with L-NAME treatment ( 3 days and 5 weeks after injury). Error bars represent standard error of the means. ${ }^{* *} p<0.005$ versus control uninjured paws, and ${ }^{\# \#} p<0.01$ versus 3 -day crush-injured paws. 


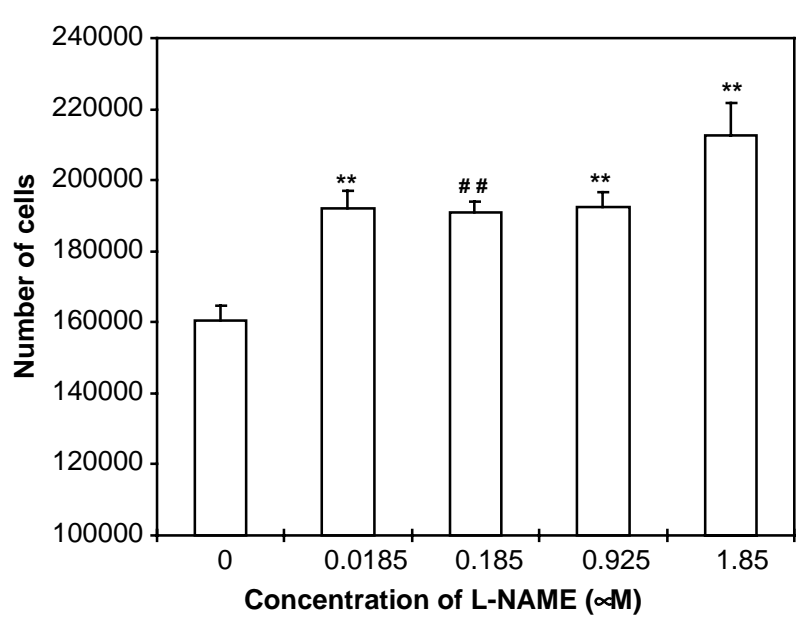

FIG. 2. Adhesion of control and L-NAME-pretreated rat peritoneal macrophages to quiescent monolayers of rat epitenon cells. Macrophages had been pretreated with different concentrations of L-NAME for 24 h. Error bars represent standard error of the means. ${ }^{* *} p<0.005$ and ${ }^{\# \#} p<$ 0.001 versus control untreated macrophages.

Increasing the concentration of L-NAME did not seem to have a much greater effect on peritoneal macrophage adhesiveness.

\section{Effects of in vivo inhibition of iNOS on adhesion of peritoneal macrophages to epitenon monolayers}

We also wished to find out whether the in vivo administration of L-NAME at the time of injury affected the adhesiveness of peritoneal macrophages, and to test this we isolated macrophages from control and L-NAME-treated rats at 3 days, 2 weeks and 5 weeks of L-NAME administration. Fig. 3 shows the adhesion of peritoneal macrophages to quiescent monolayers of rat epitenon cells. Peritoneal macrophages taken from rats that had been treated with L-

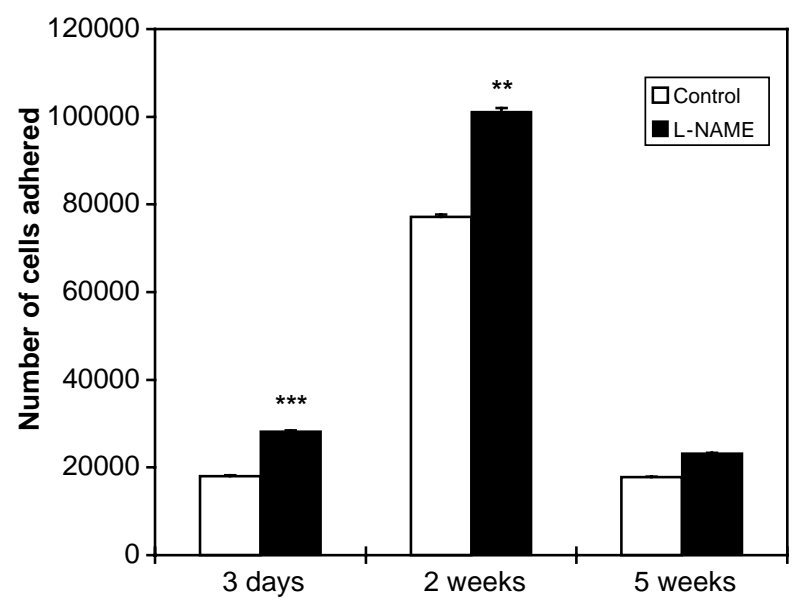

FIG. 3. Adhesion of peritoneal macrophages taken from control and L-NAME-treated rats to quiescent monolayers of rat epitenon cells. Error bars represent standard error of the means. ${ }^{* *} p<0.0025$ and ${ }^{* *} p<0.0005$ versus macrophages taken from control untreated rats.
NAME for 3 days showed a statistically significant $(p<0.0005)$ increase in adhesiveness to epitenon monolayers in comparison with control untreated rats. This increased adhesiveness was still evident at 2 and 5 weeks after L-NAME treatment, although the results were not statistically significant after 5 weeks.

\section{Discussion}

The pathophysiology of adhesion formation following tendon injury involves the accumulation of large numbers of inflammatory cells around the injured tendon and synovium, which release many cytokines and growth factors within the healing wound. TGF- $\beta$ is one of the most important cytokines in the healing wound since it appears to control the level of tissue fibrosis ${ }^{18-20}$ and, indeed, its expression in a variety of tissues has been directly linked to areas of fibrosis. ${ }^{19,21}$ We have demonstrated in this study that inhibition of nitric oxide synthesis at the time of injury leads to a chronic overexpression of TGF- $\beta$ in vivo. In control injuries, TGF- $\beta$ expression was increased in macrophages at the acute phase of the inflammatory response, and during the next 2 weeks subsequent to injury remained elevated, and by 3 weeks the TGF- $\beta$ levels decreased gradually to slightly above that observed in control uninjured paws. Inhibition of nitric oxide production by administration of L-NAME at the time of injury upset the balance and macrophages were still expressing high levels of TGF- $\beta$ at 5 weeks after the injury with no evidence of any reduction in its activity, in vivo. It is well established that chronic elevation of TGF- $\beta$ levels in the healing wound will lead to increased deposition of collagen by stimulated fibroblasts and this chronic accumulation of collagen in the healing tendon and synovium is critical in the progressive loss of function in tendon healing. The fibrotic process is tightly regulated by many factors including cytokines and circulating hormones, and the role of nitric oxide in the control of fibrosis and adhesion formation is just beginning to be investigated.

We have demonstrated that inflammatory cell infiltration into tendon, muscle and synovial tissue coincides with an increase in iNOS activity in macrophage cells. The increase in iNOS activity is greatest at the acute phase of the inflammatory response and, as the latter subsides, the iNOS activity returns to normal. Treatment with L-NAME resulted in inhibition of iNOS activity at 3 days and a reduction in the activity at the later time points examined after injury. Inhibition of iNOS activity during the early stages of tendon wound healing resulted in a chronic inflammatory response seen as late as 5 weeks after injury. ${ }^{14}$ This was reflected in our results of TGF- $\beta$ expression within the healing tendon, which showed that 
L-NAME treatment induced a chronic uncontrolled expression of TGF- $\beta$ in vivo. Nitric oxide may thus be important in exerting some sort of control on TGF- $\beta$ levels in the initial phase of tendon healing.

Craven et $a .^{22}$ reported that nitric oxide actually suppresses TGF- $\beta$ expression by inducing a marked reduction in total and active TGF- $\beta$ bioactivity in mesangial cells cultured in 5.6 or $30 \mathrm{mmol} / \mathrm{l}$ of glucose and it also suppresses increases in TGF- $\beta$ mRNA in response to culture in high concentrations of glucose. Furthermore, nitric oxide has also been reported to be antiproliferative and antifibrotic for mesangial cells in vitro. ${ }^{23-28}$

During the early phase of wound healing, nitric oxide may thus act to downregulate activity of the fibrogenic cytokine TGF- $\beta$ in the healing tendon. Indeed, the production of nitric oxide during wound healing has been reported to be important in the successful outcome of healing and, due to its many faceted biological functions, nitric oxide may delay wound repair during the early phase, but may promote healing during the more mature phase..$^{8-10}$

Studies on arginine metabolism in a rat wound healing model have demonstrated a biphasic pattern where the initial inflammatory phase was marked by activation of the L-arginine/nitric oxide pathway with an increase in nitric oxide synthase activity over the first 2-3 days after wounding, and this was followed by arginase activity during the repair phase. ${ }^{29,30}$ During the early phase of wound healing when nitric oxide synthase activity is at its highest, nitric oxide may decrease inflammatory cell adherence and transendothelial migration, and induce apoptosis in macrophages and thus reduce the inflammatory cell presence.

Although nitric oxide at nanomolar concentrations is cytoprotective, at micromolar concentrations it is cytotoxic and contributes to cell injury in a variety of disease states. ${ }^{31-33}$ Cytokines like TGF- $\beta$ that are centrally involved in tissue repair are potent inhibitors of iNOS expression and therefore play a role in teminating nitric oxide-dependent tissue injury. ${ }^{11}$ In cultured rat mesangial cells nitric oxide significantly inhibits collagen and fibronectin synthesis and increases activity of the matrix degrading enzyme gelatinase, which should decrease fibrotic matrix accumulation. $^{24-26}$ The repair promoting cytokine TGF- $\beta$ significantly increases the activity of macrophage and fibroblast arginase, ${ }^{34,35}$ and thus this cytokine may play a role in decreased cytotoxic nitric oxide production and increased repair-oriented Lornithine production. The suppression of nitric oxide is probably as important to its regulation as its induction, and the regulatory actions of TGF- $\beta$ on iNOS may be critical for controlling inflammation. ${ }^{36,37}$ In turn, a potential regulatory effect of nitric oxide on TGF- $\beta$ expression at the initial phase of tendon healing may be as critical on the outcome of successful healing.

The greatly increased levels of adhesion of inflammatory cells to tendon and muscle in vivo and to epitenon monolayers in vitro in our L-NAME studies reflect a chronic imbalance in expression of TGF- $\beta$, which is overexpressed, and nitric oxide, which is underexpressed. The physiological significance of nitric oxide biosynthesis in the course of tendon repair is only beginning to be elucidated. We have shown that formation of nitric oxide is an important event in the course of tendon healing since its inhibition results in chronic inflammation and fibrosis due to an imbalance in TGF- $\beta$ expression in vivo.

\section{References}

1. Border WA, Noble NA. Transforming growth factor $\beta$ in tissue fibrosis. $N$ Engl J Med 1994; 331: 1286-1292.

2. Klein MB, Yalamanchi N, Pham H, Longaker MT, Chang J. Flexor tendon healing in vitro: effects of TGF-beta on tendon cell collagen production. J Hand Surg [Am] 2002; 27: 615-620.

3. Chang J, Thunder R, Most D, Longaker MT, Lineaweaver WC. Studies in flexor tendon wound healing: neutralizing antibody to TGF-beta1 increases postoperative range of motion. Plast Reconstr Surg 2000; 105: $148-155$.

4. Gilbert RS, Herschman HR. Transforming growth factor beta differentially modulates the inducible nitric oxide synthase gene in distinct cell types. Biochem Biophys Res Commun 1993; 195: 380-384

5. Knowles RG, Moncada S. Nitric oxide synthases in mammals. Biochem J 1994; 298: 249-258.

6. Shi HP, Most D, Efron DT, Tantry U, Fischel MH, Barbul A. The role of iNOS in wound healing. Surgery 2001; 130: 225-229.

7. Lin JH, Wang MX, Wei A, Zhu W, Diwan AD, Murrell GA. Temporal expression of nitric oxide synthase isoforms in healing Achilles tendon. $J$ Orthop Res 2001; 19: 136-142.

8. Schaffer MR, Tantry U, Gross SS, Wasserkrug HL, Barbul A. Nitric oxide regulates wound healing. J Surg Res 1996; 63: 237-240.

9. Schaffer MR, Tantry U, Thornton FJ, Barbul A. Inhibition of nitric oxide synthesis in wounds: pharmacology and effect on accumulation of collagen in wounds in mice. Eur J Surg 1999; 165: 262-267.

10. Schaffer M, Weimer W, Wider S, Stulten C, Bongartz M, Budach W, Becker HD. Differential expression of inflammatory mediators in radiation-impaired wound healing. J Surg Res 2002; 107: 93-100.

11. Peters H, Noble NA. Dietry L-arginine in renal disease. Seminars Nephrol 1996; 16: $567-575$.

12. Ferrini MG, Vernet D, Magee TR, Shahed A, Qian A, Rajfer J, GonzalezCadavid NF. Antifibrotic role of inducible nitric oxide synthase. Nitric Oxide 2002; 6: 283-294.

13. Peters H, Daig U, Martini S, et al. NO mediates antifibrotic actions of Larginine supplementation following induction of anti-thy1 glomerulonephritis. Kidney Int 2003; 64: 509-518.

14. Darmani H, Crossan JC, Curtis A. Single dose of iNOS inhibitor induces prolonged inflammatory cell accumulation and fibrosis around injured tendon and synovium. Mediat Inflamm 2004; 13: 157-164.

15. Banes AJ, Donlon K, Link GW, et al. Cell populations of tendon-a simplified method for isolation of synovial cells and internal fibroblasts: confirmation of origin and biologic properties. J Orthopaed Res 1988; 6: 83-94.

16. Wojciak B, Crossan J. The accumulation of inflammatory cells in synovial sheath and epitenon during adhesion formation in healing rat flexor tendons. Clin Exp Immunol 1993; 93: 108.

17. Westergren-Thorsson G, Onnervik PO, Fransson LA, Malmstrom A. Proliferation of accumulated fibroblasts is inhibited by L-iduronatecontaining glycosaminoglycans. J Cell Physiol 1991; 147: 523-530.

18. Wahl SM. Transforming growth factor beta in inflammation. A cause and a cure. J Clin Immunol 1992; 12: 61.

19. Brahmatewari J, Serafini A, Serralta V, Mertz PM, Eaglstein WH. The effects of topical transforming growth factor-beta2 and anti-transforming growth factor-beta 2,3 on scarring in pigs. J Cutan Med Surg 2000; $\mathbf{4}$ : $126-131$.

20. Chamberlain J. Transforming growth factor-beta: a promising target for anti-stenosis therapy. Cardiovasc Drug Rev 2001; 19: 329-344.

21. Border WA, Ruoslahti E. Transforming growth factor- $\beta$ in disease: the dark side of tissue repair. J Clin Invest 1992; 90: 1-7. 
22. Craven PA, Struder RK, Felder J, Phillips S, DeRubertis FR. Nitric oxide inhibition of transforming growth factor- $\beta$ and collagen synthesis in mesangial cells. Diabetes 1997; 46: 671-681.

23. Garg UC, Hassid A. Inhibiting of rat mesangial cell mitogenesis by nitric oxide-generating vasodilators. Am J Physiol 1989; 257: F60-F66.

24. Trachtman H, Futterweit S, Singhal P. Nitric oxide modulates the synthesis of extracellular matrix proteins in cultured rat mesangial cells. Biochem Biophys Res Commun 1995; 207: 120-125.

25. Trachtman H, Futterweit S, Garg P, Reddy K, Singhal PC. Nitric oxide stimulates the activity of a $72 \mathrm{kda}$ neutral matrix metalloproteinase in cultured rat mesangial cells. Biochem Biophys Res Commun 1996; 218 . $704-708$.

26. Trachtman H, Futterweit S, Singhal PC, Franki N, Sharma M, Sharma R, Savin V. Circulating factor in patients with recurrent focal segmental glomerulosclerosis postrenal transplantation inhibits expression of inducible nitric oxide synthase and nitric oxide production by cultured rat mesangial cells. J Investig Med 1999; 47: 114-120.

27. Chin TY, Lin YS, Chueh SH. Antiproliferative effect of nitric oxide on rat glomerular mesangial cells via inhibition of mitogen-activated protein kinase. Eur J Biochem 2001; 268: 6358-6368.

28. Keil A, Blom IE, Goldschmeding R, Rupprecht HD. Nitric oxide downregulates connective tissue growth factor in rat mesangial cells. Kidney Int 2002; 62: 401-411.

29. Albina JE, Mills CD, Barbul A, Thirkill CE, Henry WL, Mastrofrancesco B, Caidwell MD Arginine metabolism in wounds. Am J Physiol 1988; 17: $\mathrm{E} 459-\mathrm{E} 467$.

30. Albina JE, Mills CD, Henry WL, Caldwell MD. Temporal expression of different pathways of L-arginine metabolism in healing wounds. $J$ Immunol 1990; 144: 3877-3880.
31. Lefer DJ, Scalia R, Campbell B, et al. Peroxynitrite inhibits leukocyteendothelial cell interactions and protects against ischemia-reperfusion injury in rats. J Clin Invest 1997; 99: 684-691.

32. Ma XL, Gao F, Lopez BL, Christopher TA, Vinten-Johansen J. Peroxynitrite, a two-edged sword in post-ischemic myocardial injury-dichotomy of action in crystalloid- versus blood-perfused hearts. J Pharmacol Exp Ther 2000; 292: 912-920.

33. Zweier JL, Fertmann J, Wei G. Nitric oxide and peroxynitrite in postischemic myocardium. Antioxid Redox Signal 2001; 3: 11-22.

34. Boutard V, Havouis R, Fouqueray B, Philippe C, Moulinoux JP, Baud L. Transforming growth factor-beta stimulates arginase activity in macrophages. Implications for the regulation of macrophage cytotoxicity. $J$ Immunol 1995; 155: 2077-2084.

35. Witte MB, Barbul A, Schick MA, Vogt N, Becker HD. Upregulation of arginase expression in wound-derived fibroblasts. J Surg Res 2002; 105: $35-42$.

36. Vodovotz Y, Bogdan C, Paik J, Xie Q-W, Nathan C. Mechanisms of suppression of macrophage nitric oxide release by transforming growth factor- $\beta$. J Exp Med 1993; 178: 605-613.

37. Vodovotz Y. Control of nitric oxide production by transforming growth factor-beta1: mechanistic insights and potential relevance to human disease. Nitric Oxide 1997; 1: 3-17.

\section{Received 4 May 2004 \\ Accepted 6 July 2004}




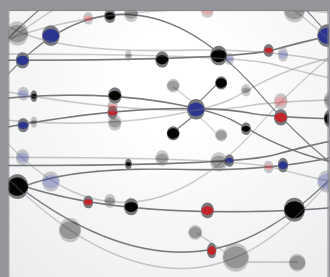

The Scientific World Journal
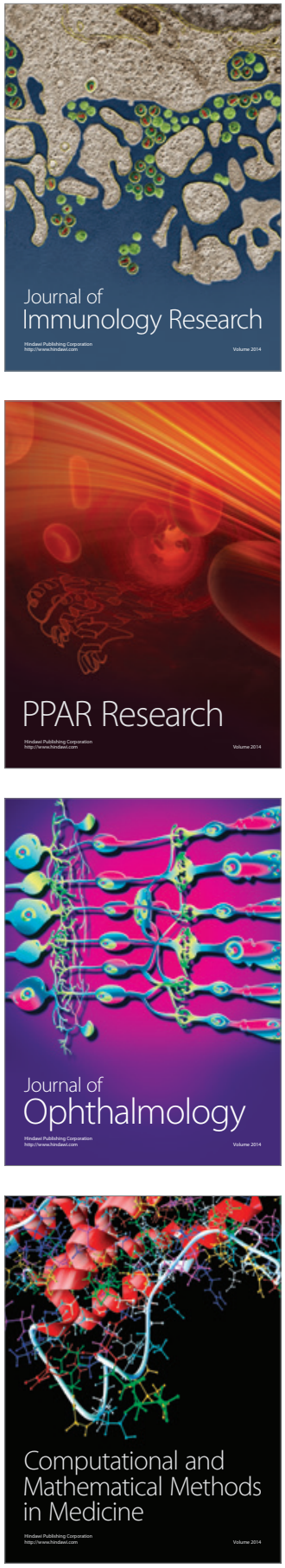

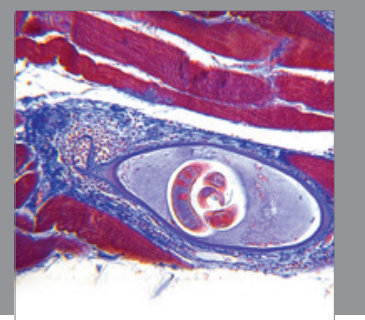

Gastroenterology

Research and Practice
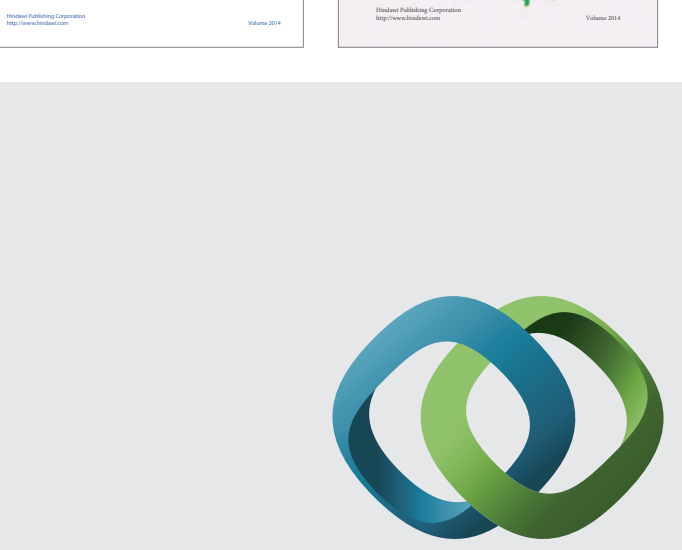

\section{Hindawi}

Submit your manuscripts at

http://www.hindawi.com
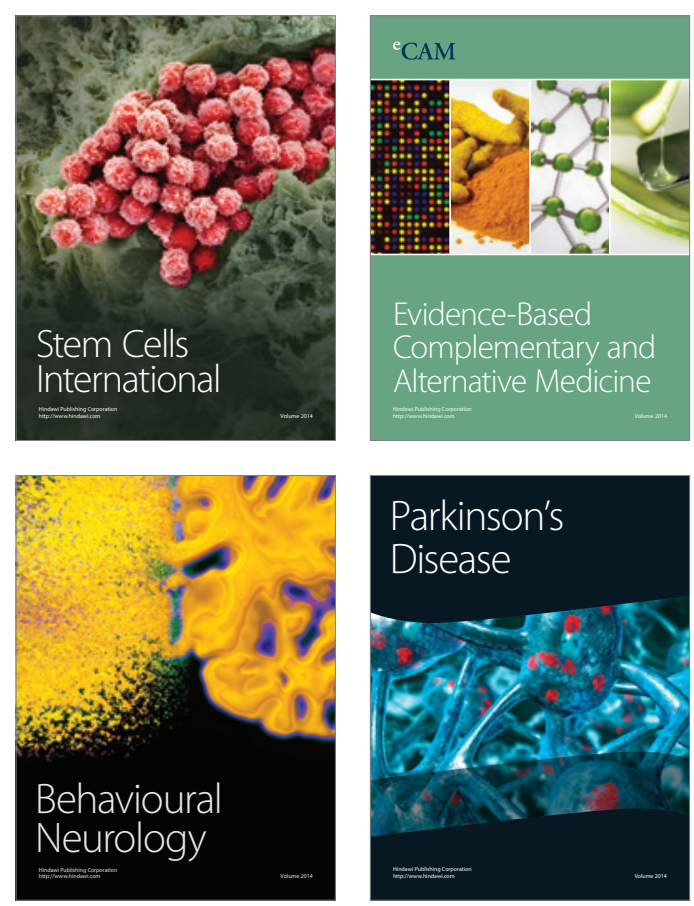

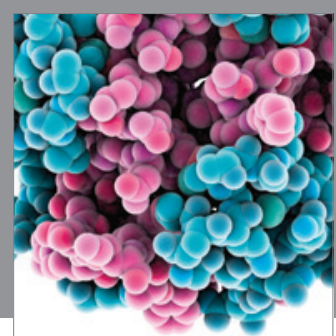

Journal of
Diabetes Research

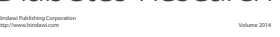

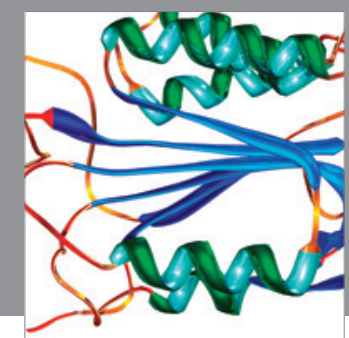

Disease Markers
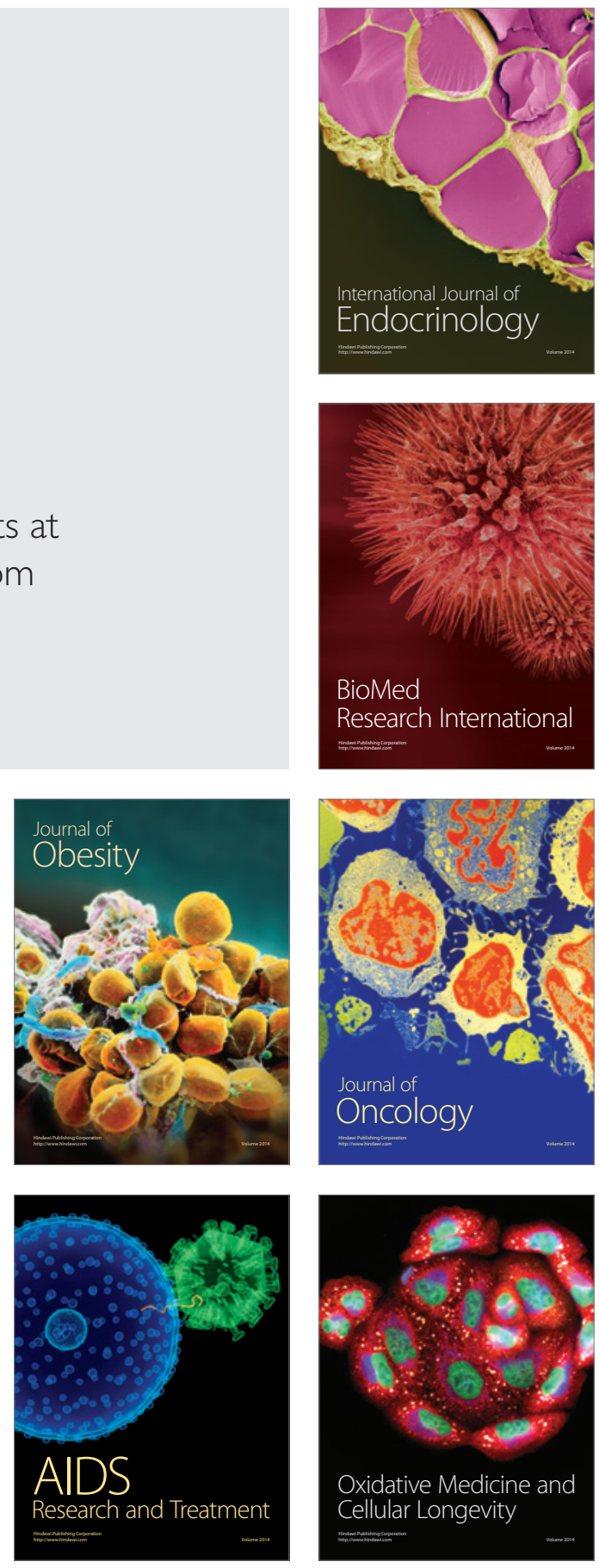